\title{
Comparative Study for Different Antenna Designs for the 4G Networks
}

\author{
Sara Alzahrani \\ Department of Electrical and \\ Computer Engineering, \\ King Abdulaziz University, \\ Jeddah, KSA
}

\author{
Hanan Ahmed \\ Department of Electrical and \\ Computer Engineering, \\ King Abdulaziz University, \\ Jeddah, KSA
}

\author{
Hebah Alnahdi \\ Department of Electrical and \\ Computer Engineering, \\ King Abdulaziz University, \\ Jeddah, KSA
}

\author{
Roaa Alamoudi \\ Department of Electrical and \\ Computer Engineering, \\ King Abdulaziz University, \\ Jeddah, KSA
}

\author{
Hemalatha M. \\ Department of Electrical and \\ Computer Engineering, FOE, \\ King Abdulaziz University, \\ Jeddah, KSA
}

\begin{abstract}
Wireless communication has become an inevitable part of our lives. Since the evolution of patch antennas, there has been rapid growth observed in its application. There are many advantages of wireless communication such as the small size, ease of fabrication and installation, and firm performance. There are several designs that have been developed and presented by researchers over time. In this report, different antenna designs for the $4 \mathrm{G}$ network will be presented with their specific features and applications.
\end{abstract}

\section{Keywords}

Wireless communications, 4G, wideband frequency.

\section{INTRODUCTION}

Wireless communication began in the early 20th century when Nikola Tesla discovered that energy could be transferred by electromagnetic waves without the need for conductors. At that time, his ideas were not considered; however, they were responsible for paving the way for the development of wireless power transmission technology. Over the past few years, wireless communication has witnessed an incredible increase that was followed by an increase in antennas design demand. Antennas are major components of a wireless communication; coordinating electromagnetic waves between communication devices through the air. Antennas are of various kinds and have different attributes according to the desired application and range of frequency. Therefore, in antenna design there are many aspects that must be taken into consideration, such as the performance enhancement of the transceiver devices, cost and size reduction. Antennas are developed from periodically due to their importance in wireless communications. Among the various applications which the antenna can be designed for includes radio, television, satellite, broadcasting, and cellular system etc.

\section{DIFFERENT ANTENNA DESIGNS FOR THE 4G NETWORKS}

This paper presents a comparative analysis of various patch antennas, designed for fourth generation $(4 \mathrm{G})$ technology, that can be differentiated with respect to their shapes, material used, signal and bandwidth.

\subsection{First Design: Dual Rectangular Ring Microstrip Antenna with Defected Ground Structure (DGS) Design}

This section presents a (DGS) design and analysis for wireless applications [1]. The readymade software tool that was used to simulate and analyze the design is called a Computer Simulation Tool (CST). The design used two rectangular rings as a patch as shown in Figure 1. The feed line and DGS techniques were applied to enhance the performance. This antenna was designed for $3 \mathrm{G}$ and $4 \mathrm{G}$ bands. The design was implemented by using FR-4 substrate material with dielectric constant of 4.7 , thickness $\mathrm{h}=0.8 \mathrm{~mm}$, and tangent loss 0.019 . The antenna design performance was investigated in terms of return loss.

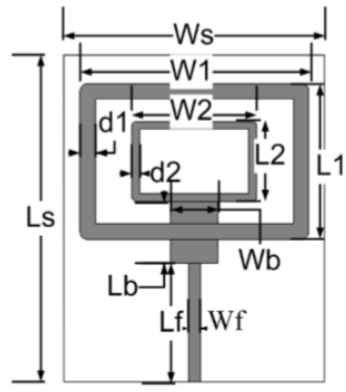

Top view

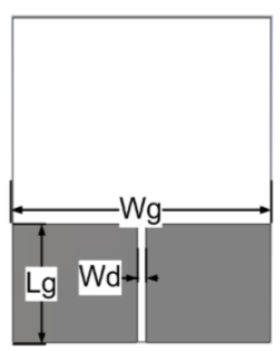

Bottom view

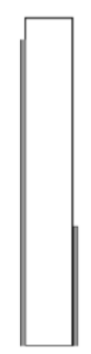

Side
Figure 1. The proposed antenna design [1].

As shown in the above figure, the design consists of two rectangles inside each other. The design ground panel contains a thin DGS. The feeder is a $50 \Omega$ micro-strip line etched on the FR-4 material. There are view equations that have been used to get the initial width and length of the patch before optimizing the dimensions to get the desired resonant frequency [2]. The initial length of feed line was 0.717 ratio of FR-4 material whereas the width was obtained by using a reference equation [2]. The feed line width has been optimized to obtain $50 \Omega$ matching impedance. The DGS was proposed to enhance the directivity and the gain [1]. The simulation result shows that the return loss is less than $-10 \mathrm{~dB}$ 
in the range of $1.95-3.75 \mathrm{GHz}$ that is very good since it indicates that the reflected power is less than $10 \%$.

The main goal in developing this design is to enhance the bandwidth within an acceptable gain [3]. The design operated at the frequency range $1.9 \mathrm{GHz}-3.6 \mathrm{GHz}$ and was of a small size with a higher bandwidth, which was found to be a good feature.

\subsection{Second Design: Wideband T-Slot Antenna for 4G Applications}

In this design, a rectangular bandwidth patch slot antenna for $4 \mathrm{G}$ applications has been designed at the frequency of 1.72 $\mathrm{GHz}$ up to $2.85 \mathrm{GHz}$ to enhance the impedance bandwidth and gain. The proposed antenna contains a $\mathrm{T}$-shape resonator fed by a coplanar waveguide. The design was implemented on permittivity of $\varepsilon \mathrm{r}=4.3 \mathrm{~mm}$ and thickness of thk $=1.6 \mathrm{~mm}$ by using the FR-4 substrate. The proposed antenna was designed with a $47 \mathrm{~mm}$ width and $45 \mathrm{~mm}$ length, as shown in Figure 2.

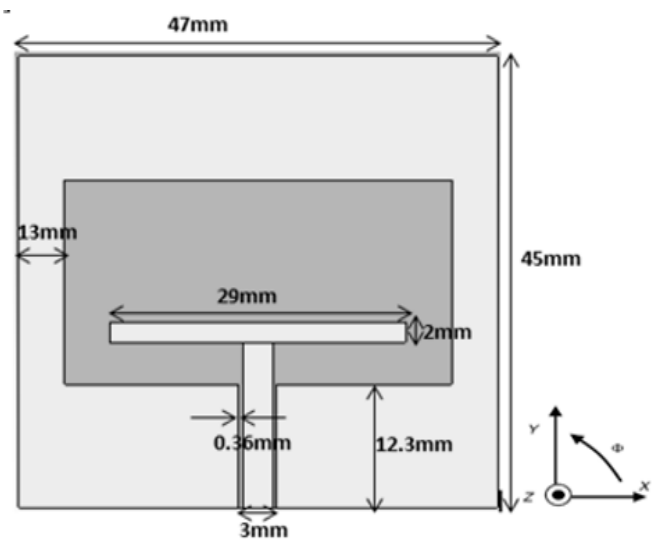

Figure 2. Structure of the proposed antenna [4].

The T-slot was introduced on the patch surfaces to improve bandwidth that could be utilized in many wideband applications [5, 6]. The dimensions of the T-slot were $29 \mathrm{~mm}$ width and $2 \mathrm{~m}$ length for the rectangular patch design and 3 $\mathrm{mm}$ width, which was connected to a $50 \Omega$ Waveguide (CPW)-feed line. The dimensions of the slot were crucial for the return losses of a micro-strip. The return losses were decreased after decreasing the length and increasing the width and vice versa. In this design, the result of the return loss was accepted at the band of $1.72 \mathrm{GHz}-2.85 \mathrm{GHz}$, which was less than $-10 \mathrm{~dB}$. Thus, the result of the antenna, was affected by changing the dimension of the slot. The proposed antenna design was simple to design and manufacture, lightweight and low cost [4].

\subsection{Third Design: Miniature Wideband 1x2 Micro-Strip Antenna}

A 1x2-miniature wideband antenna was implemented with several techniques such as; Electronic Band-gap Structure (EBGs) between the antennas [10], a partial ground plane at micro-strip feeder, and slotted ring in the EBG patches [11]. The miniaturization rectangular patch antenna was designed by using the FR-4 substrate material, dielectric constant 4.4, thickness $1.6 \mathrm{~mm}$, loss tangent 0.02 , and $50 \Omega$ impedance of the transmission line.

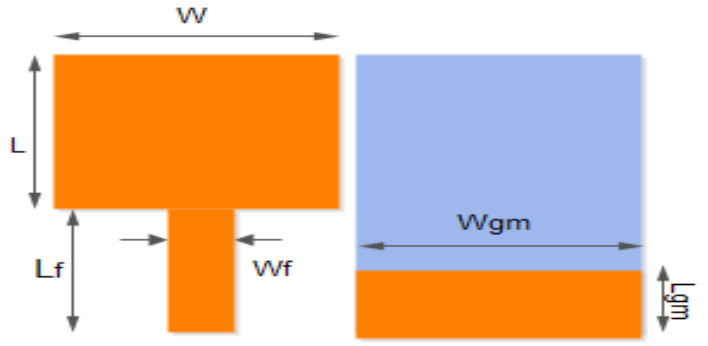

Figure 3. Partial ground plane patch antenna $(W=8 \mathrm{~mm}$, $\mathrm{L}=5 \mathrm{~mm}, \mathrm{Wf}=1.6 \mathrm{~mm}, \mathrm{f}=10 \mathrm{~mm}, \mathrm{Wgm}=17.6 \mathrm{~mm}$ and Lgm=6mm) [12].

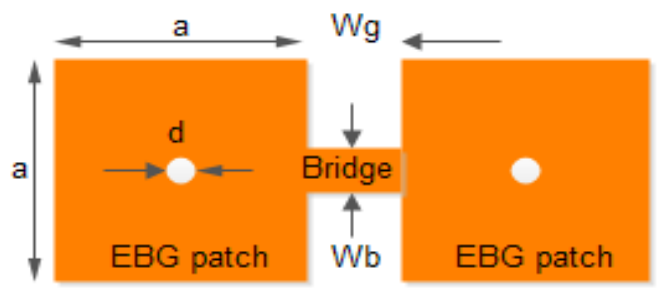

Figure 4. Bridge connection between two unit cells $(a=4 \mathrm{~mm}, W g=1 \mathrm{~mm}, d=0.2 \mathrm{~mm}, W b=0.25 \mathrm{~mm}$ and $\mathrm{d}=\mathbf{0 . 2} \mathrm{mm}$ )

The antenna was formed in three stages. The first stage was, a single element designed with a partial ground plane to investigate additional effects of reactance, as shown in Figure 3 , the dimensions of a partial ground $(\mathrm{Wgm}=17.6 \mathrm{~mm}$ and $\mathrm{Lgm}=6 \mathrm{~mm}$ ). In the second stage, a mushroom type EBG structure was designed that consisted of periodic mineral patches that were separated by specific gaps with common ground to augment the radiation efficiency of the patches, as shown in Figure 4. The third stage contained two single patches and two $1 \times 2$ monopole antennas, which inserted on the common T-shape partial ground plane and common substrate, the specification is shown in Figure 5 and 6 , respectively.

The miniaturization antenna remains as the main advantage of this design. It reduced the size of the antenna by more than $83 \%$ with a good radiation characteristic by using a $1 \times 2$ Micro-strip Antenna or more antennas. The design had a return loss of $-10 \mathrm{~dB}$ in the operating band $(3.8 \mathrm{GHz}$ to 7.9 $\mathrm{GHz}$ ) which is considered to be a good response. Furthermore, placing an EBG structure between the patches improved the performance of the capacitive reactance on the patches.

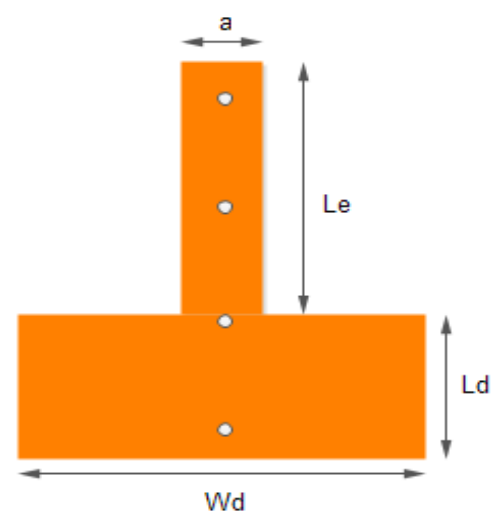

Figure 5. Ground plane of 1x2 patch antennas with EBG Structure $(\mathrm{Ld}=\mathbf{8 m m}, \mathrm{Wd}=17.6 \mathrm{~mm}, \mathrm{Le}=11.6 \mathrm{~mm}$ and $\mathrm{a}=4 \mathrm{~mm})[12]$. 


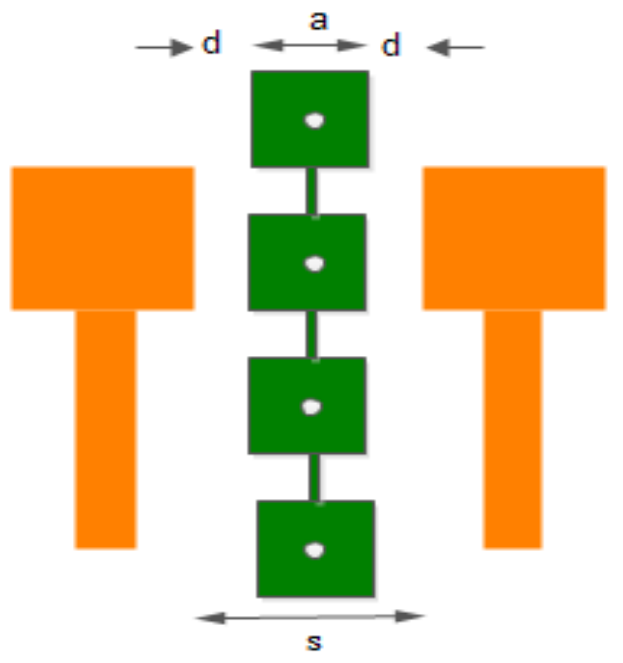

Figure 6. Structure of $1 \times 2$ rectangular patch antenna with EBG Structure $(d=0.5 \mathrm{~mm}, a=4 \mathrm{~mm}$ and $s=5 \mathrm{~mm})[12]$.

\subsection{Fourth Design: A Compact Dual-Band Monopole Antenna}

This design is a Coplanar CPW-fed monopole antenna, which was designed with dual-band for Wi-Fi and 4G Long-Term Evolution-LTE. The circular patch antenna contains a U-slot with various grounds to get a better impedance match, and has a compact size $30 \times 28.38 \times 1.5 \mathrm{~mm} 3$. The operation of the dual-band antenna was appropriate for Wi-Fi bands $2.4 \mathrm{GHz}$ $2.484 \mathrm{GHz}$ and $5.15 \mathrm{GHz}-5.875 \mathrm{GHz}$ and $4 \mathrm{G} \mathrm{LTE}$ band $2.5 \mathrm{GHz}$ $-2.69 \mathrm{GHz}[7,8]$.

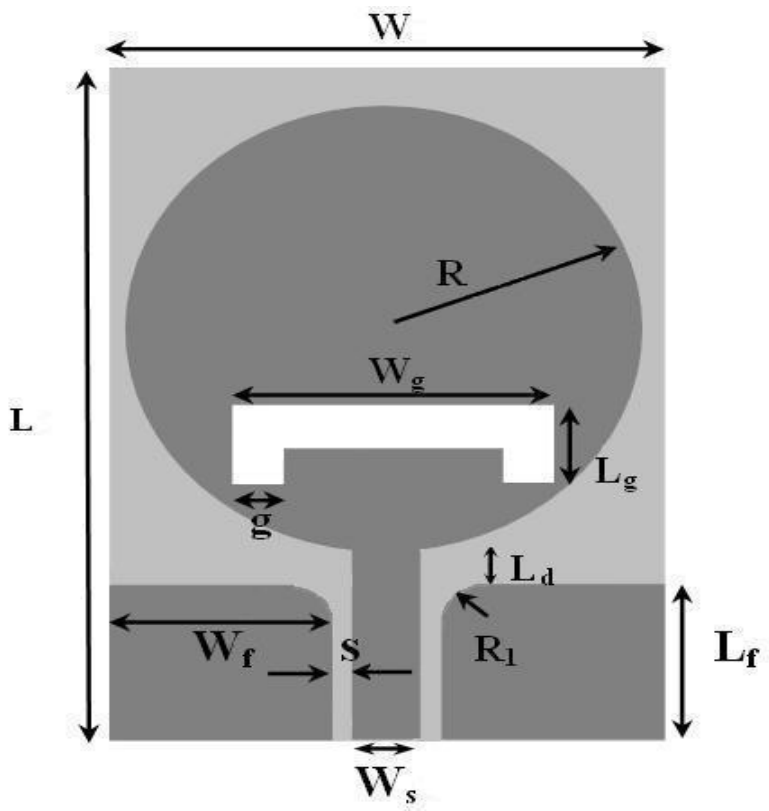

Figure 7. Structure of the compact dual-band antenna [7].

The Specification of the antenna design which is shown in Figure 7.used are: FR-4 as a dielectric substrate, which have a loss tangent of 0.0019 and dielectric constant of 2.25 , with a small size of $30 \times 28.38 \times 1.5 \mathrm{~mm} 3$. The s gap printed between the coplanar ground plane and the feed line of Ws strip width to get $50 \mathrm{ohms}$ impedance [7].
This design has many advantages such as low thickness, a miniaturized size and low cost. The design has a return loss of $-20 \mathrm{~dB}$ at $2.46 \mathrm{GHz}$ in the low frequency band with a $1 \mathrm{GHz}$ bandwidth. Moreover, the return loss was around $-25 \mathrm{~dB}$ at a high frequency band, with a $1.5 \mathrm{GHz}$ bandwidth. In addition, the dual-band antenna could be operated in other frequency bands by adjusting the diminutions [7,9].

\section{CONCLUSION}

This paper has presented various designs for the patch antenna each with their own specifications and attributes. In the first design, an antenna with DGS was presented. That design operated at the range of frequency $1.95-3.75 \mathrm{GHz}$ and had an acceptable return loss response, which is less than $-10 \mathrm{~dB}$. The unique aspect of this design was the DGS switch was introduced to improve the bandwidth. The second design that was presented is a wideband slot antenna that operated at the range of frequency $1.72-2.85 \mathrm{GHz}$. The unique aspect of this design is the T-slot that was introduced on the patch surfaces, which is another technique used to improve the bandwidth. The third design was a miniature wide-band $1 \times 2$ antenna that was implemented with several techniques such as; EBGs in between the two antennas, a partial ground plane at the microstrip feeding, and slotted ring in the EBG patches. This design has several advantages like the small size with good radiation characteristics. The design operates in the frequency band from $3.8 \mathrm{GHz}$ to $7.9 \mathrm{GHz}$ and has a return loss of $-10 \mathrm{~dB}$ in the same operating band. The last design is a compact dualband monopole antenna that works in the $2.28 \mathrm{GHz}$ to 2.82 $\mathrm{GHz}$ band and $3.87 \mathrm{GHz}$ to $6.0 \mathrm{GHz}$ band. The unique feature in this design is the slotted U-form in the circular patch with $\mathrm{CPW}$-fed to promote the performance of matching impedance and bandwidth. The design shows a return loss less than -20 $\mathrm{dB}$ in all the operating bands. Therefore, all four designs were found to be suitable for the $4 \mathrm{G}$ network applications. For future development, the gain can be enhanced by implementing an array from the single element and by implementing different patch shapes to improve the performance.

\section{REFERENCES}

[1] M. K. Mohamed Amin, M. T. Ali, S. Saripuden, A.A Ab Aziz "Design of Dual Rectangular Ring Antenna with DGS Technique for Wireless Application", IEEE Symposium on Wireless Technology and Applications (ISWTA), Bandung, Indonesia, September 23-26, 2012.

[2] B. C.A., Antenna Theory: Analysis and Design, 3rd edition ed., Hoboken, New Jersey, A John Wiley \& Sons, INC., 2005.

[3] S. K. Singh and A. K. Singh, "Multiband Rectangular Ring Microstrip Antenna for UWB Wireless Applications," in Progress In Electromagnetics Research Symposium, Beijing, 2009.

[4] Sahar Chagharvand, M. R. Hamid, M. R. Kamarudin, Mohsen Khalily, "Wideband Slot Antenna for 4G Applications".Sahar Chagharvand1, M. R. Hamid2, M. R. Kamarudin3, Mohsen Khalily4, 2014.

[5] F. Li, Y. C. Jiao, L. S. Ren, J. G. Gong, and B. Chen, "Compact double T-shaped slots antenna with a rectangular patch for bandwidth enhancement", pp. 286288, 2010.

[6] P.Vetriselvi, Sathiyamoorthy Murugan., Dr.V.Rajamani, "Design Of Wideband U Slot Microstrip Antenna " IJIRSET, pp 1382- 1386, 2014. 
[7] Yuan. Zhu, Min. Quan. Li, Hong. Qing. He," A compact dual-band monopole antenna for 4G LTE and WIFI utilizations", IEEE Antennas Wireless Propagation Letter, 2017-1-16.

[8] H.W. Liu, C.H. Ku, and C. F. Yang, "Novel CPW-fed planar monopole antenna for WIMAX/WLAN application" IEEE Antennas Wireless Propagation Letter, vol.9, pp. 240-243, 2010.

[9] Sun, M., Zhang, Y.P., Lu, Y. "Miniaturization of planar monopole antenna for ultra wideband radios", IEEE Trans. Antennas Propag, 58, (7), pp. 2420-2425, 2010.

[10] Nagendra kushwaha1 and Raj Kumar2 ," Study of Different Shape Electromagnetic Band Gap (EBG)
Structures for Single and Dual band Applications", Journal of Microwaves, Optoelectronics and Electromagnetic Applications, Vol. 13, No. 1, June 2014

[11] Y. Sung, "A Printed Wide-Slot Antenna with a Modified Lshaped Micro-strip Line for Wideband Application", IEEE Transaction on Antennas and Propagation, Vol.59, No.10, October 2011.

[12] Jayendra Kumar, S.S. Shirgan, Deepak B. Patil," Miniature Wideband 1x2 Micro-strip Antenna for 4GApplication", IEEE Global Conference on Wireless Computing and Networking (GCWCN), 2014. 